\title{
Nitrosyl chloride addition to cycloalkenyltrimethylsilanes. An unexpected reversal of regiochemistry of addition, and synthesis of $\beta$-aminosilanes
}

\author{
M. Narendra Mallya, and Gopalpur Nagendrappa* \\ Department of Chemistry, Bangalore University, (Central College Campus), \\ Bangalore 560 001, India \\ E-mail: gnagendrappa@gmail.com
}

\begin{abstract}
Cycloalkenyltrimethylsilanes add nitrosyl chloride stereo- and regio- selectively. The addition is $s y n$, with chlorine and nitrosyl group adding to $\mathrm{C}-1$ and $\mathrm{C}-2$ respectively. The products dimerize to diazene dioxides, whose stability depends on the conformational flexibility of the ring - the less flexible are more stable. The less stable adducts convert to oximes and further to 1,2dichloro-1-nitrosocycloalkanes. The adducts can be hydrolysed to $\alpha$-chloroketones and reduced to $\beta$-aminosilanes. Other interesting observations include transposition of keto group in $\alpha$ chloroketones and X-ray crystal structure of the amide derivative $6 \mathbf{f}$, which reveals - $(\mathrm{CO})$ $\mathrm{HN}$...H-CH $2-(\mathrm{CO})-$ hydrogen contact.
\end{abstract}

Keywords: Cycloalkenyltrimethylsilanes, NOCl addition, $\alpha$-chloro- $\beta$-nitrososilanes, 1,2dichloro-1-nitrosocycloalkanes, $\alpha$-chloroketones, conformational flexibility, $\beta$-aminosilanes, N...H-C hydrogen contact

\section{Introduction}

1-Chloro-2-nitroso compounds obtained by a simple addition reaction of nitrosyl chloride $(\mathrm{NOCl})$ with olefins are versatile compounds and find many synthetic applications. ${ }^{1-3}$ In pure state, the adducts exist usually in the form of dimers, called diazene dioxides, resulting from N-N connection and are stable substances (Scheme 1). 


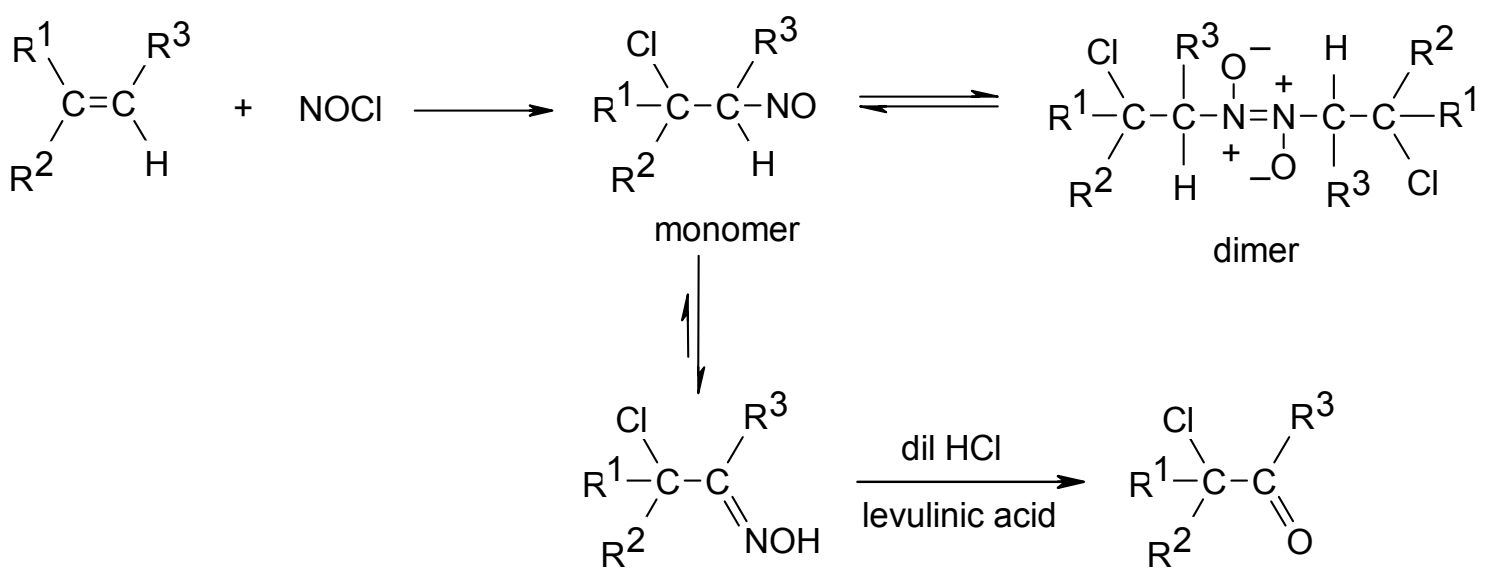

\section{Scheme 1}

The dimeric form is retained even in solution, though it may dissociate into monomer and equilibrium would be established between the two forms. The monomer in solution may undergo tautomerization (if $\alpha$-hydrogen is present) to the corresponding oxime, which is however essentially irreversible. ${ }^{3}$ The oxime is generally much more stable than the nitroso compound. Nonetheless, the nitroso-to-oxime tautomerization is not a spontaneous process, and is catalyzed by acid or base. The ease of tautomerization also depends to some extent on the alkene structure. The $\alpha$-chlorooxime can eventually be hydrolyzed to $\alpha$-chloroketone ${ }^{4}$ or used in other ways. ${ }^{3}$ The $\mathrm{NOCl}$ addition to alkene is shown to be $\operatorname{trans}^{1-3}$ as well as cis, ${ }^{5,6}$ and usually follows Markovnikov regiochemistry ${ }^{2,7}$ as a result of which the $\alpha$-chloroketone would have regio-defined structure.

In an earlier report we showed that $\mathrm{NOCl}$ addition to cycloalkenyltrimethylsilanes is both stereoselective and regioselective, in that, the reagent adds in a cis manner with $\mathrm{NO}$ attaching to the $\beta$-carbon and $\mathrm{Cl}$ to the $\alpha$-carbon, ${ }^{8}$ (Scheme 2 ). Both these selectivity outcomes are contrary to expectation in view of the $\beta$-silicon effect, ${ }^{9}$ with electrophile adding to $\alpha$-carbon in favour of $\beta$-cation formation. 


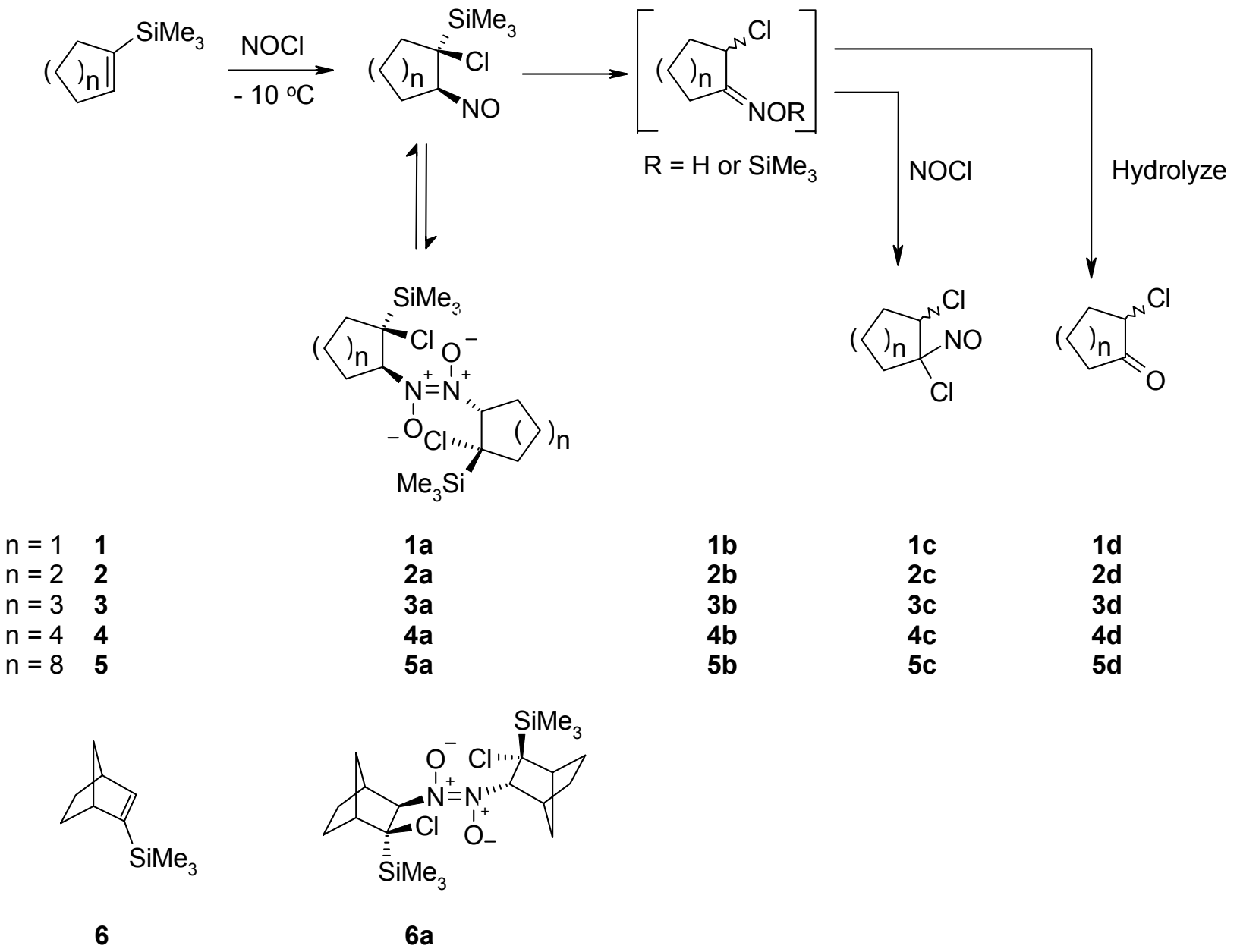

\section{Scheme 2}

During this study we noted that the $\alpha$-chloro- $\beta$-nitrososilanes 1a-5a were far less stable than their unsilylated analogues, and underwent further reaction very rapidly to give finally 1,2dichloro-1-nitrosocycloalkanes 1c-5c and, under aqueous condition, $\alpha$-chloroketones 1d-5d presumably through the intermediacy of the oxime $\mathbf{1 b - 5 b}$. The directive influence of silicon in this transformation is easily recognizable. Our further study has revealed that the relatively close location of the silyl moiety and NO group, which is determined by the conformation of the ring, is crucial for this to be successful. We have also observed that through this sequence of reaction, a 1,2-migration of keto group can be achieved. ${ }^{10}$

In addition, the $\alpha$-chloro- $\beta$-nitrososilanes are potential precursors for both $\alpha$ - as well as $\beta$ functionalized silanes. Among the $\beta$-functionalized silanes, $\beta$-aminosilanes have not been studied much. Very few reports are found in the literature on synthesis of $\beta$-aminosilanes. ${ }^{11}$ The reduction of $\beta$-nitroso group to amino function in $\alpha$-chloro- $\beta$-nitrososilanes $1 \mathbf{a}-6 \mathbf{a}$ adducts provides a convenient method for making $\beta$-aminosilanes. The spectral investigations of the well-characterized solid derivatives of the $\beta$-aminosilanes were used to further confirm and 
establish the regiochemistry and stereochemistry of $\mathrm{NOCl}$ addition to cycloalkenyltrimethylsilanes 1-6.

\section{Results and Discussion}

The effective influence of silyl substituent in a ring system on a functional group or at a reaction site in cyclic systems has been shown to depend on the ring size in a crucial way, because the orientation of the silyl group relative to the functional group or its reactivity is determined by the conformational characteristics of the ring. ${ }^{12,13}$ Our earlier study on the kinetics of a host of cyclic 1,2-dihydroxysilanes demonstrates the dependence of the rates on the conformational flexibility of the rings, which determines the correct orientation for the silanol elimination. ${ }^{14}$ Thus a series of cycloalkenyltrimethylsilanes such as 1-6 or monomers of 1a-6a would yield much information on the conformational requirement for the silyl group to influence the reaction dealt in this paper.

To study the effect of silicon on nitroso-oxime tautomerism, we have chosen six cyclic systems 1a-6a comprising very rigid system (6a) to highly flexible ring structures. $\alpha$-Chloro- $\beta$ nitrosotrimethylsilylcycloalkanes 1a-6a were prepared by adding $\mathrm{NOCl}$ to cycloalkenyltrimethylsilanes 1-6 (Scheme 2).

The source of $\mathrm{NOCl}$ was the well-known in situ reaction of iso-amylnitrite with acetic acidconc $\mathrm{HCl}$ mixture in one procedure. $\mathrm{NOCl}$ was also generated under anhydrous condition by treating iso-amylnitrite with chlorotrimethylsilane ${ }^{15}$ either in dichloromethane or neat. The reactions were carried out between $-20{ }^{\circ} \mathrm{C}$ and $-10{ }^{\circ} \mathrm{C}$. Though the formation of monomeric nitroso compounds could be easily recognized initially by their characteristic blue colour, ${ }^{16}$ only white dimeric diazene dioxides 1a-6a and /or their secondary products, the 1,2-dichloro-1nitroso derivatives $\mathbf{1 c - 5 c}$ and $\alpha$-chloroketones $\mathbf{1 d - 5 d}$, could be isolated. The yields and proportions of the products varied according to the method of generation of $\mathrm{NOCl}$, and the ring size of adduct. The results are summarized in Table 1.

The $\mathrm{NOCl}$ addition to 1-trimethylsilylcycloalkenes 1-5 under aqueous acidic condition (Method A) produces secondary products $\mathbf{1 c - 5 c}$ and $\mathbf{1 d - 5 d}$ in high proportion, while under the anhydrous condition of Method $\mathrm{C}$ in $\mathrm{CH}_{2} \mathrm{Cl}_{2}$ solvent, the 1,2-dichloro-1-nitroso derivatives 1c-5c are the only products. It is obvious that the presence of water in Method A is responsible for the formation of $\alpha$-chloroketones $\mathbf{1 d - 5 d}$, whereas under anhydrous condition employed in the other two procedures, no $\alpha$-chloroketones are formed.

It should be noted at this stage that the results of six membered ring (2) and norbornane ring (6) systems stand out, in that the former gives no trace of primary adduct 2a but only products $\mathbf{2 c}$ and $\mathbf{2 d}$ of further reactions of $\mathbf{2 a}$, while the latter (6) gives only the stable dimeric primary adduct 6a. 
Table 1. NOCl addition to cycloalkenyltrimethylsilanes 1-6

\begin{tabular}{|c|c|c|c|c|c|}
\hline Vinylsilane & Method $^{\mathrm{a}}$ & Time (h) & & $\begin{array}{l}\text { Product(s) } \\
\text { (Yield, \%) }\end{array}$ & \\
\hline \multirow[t]{4}{*}{1} & & & $1 \mathrm{a}$ & $1 \mathrm{c}$ & 1d \\
\hline & A & 2.0 & 35 & 20 & 35 \\
\hline & B & 1.5 & 52 & 40 & - \\
\hline & $\mathrm{C}$ & 2.5 & - & 89 & - \\
\hline \multirow[t]{4}{*}{2} & & & $2 a$ & $2 c$ & 2d \\
\hline & A & 2.0 & - & 60 & 35 \\
\hline & $\mathrm{B}$ & 1.5 & - & 85 & - \\
\hline & $\mathrm{C}$ & 2.0 & - & 90 & - \\
\hline \multirow[t]{4}{*}{3} & & & $3 \mathbf{a}$ & $3 c$ & $3 d$ \\
\hline & A & 1.5 & 30 & 25 & 35 \\
\hline & B & 1.5 & 65 & 30 & - \\
\hline & $\mathrm{C}$ & 2.5 & - & 76 & - \\
\hline \multirow[t]{4}{*}{4} & & & $4 a$ & $4 c$ & $4 d$ \\
\hline & A & 2.0 & 65 & 25 & 10 \\
\hline & B & 1.5 & 75 & 25 & - \\
\hline & $\mathrm{C}$ & 2.5 & - & 55 & - \\
\hline \multirow[t]{4}{*}{$5^{\mathrm{b}}$} & & & $5 \mathbf{a}$ & $5 c$ & 5d \\
\hline & A & 5.0 & 6 & 25 & 35 \\
\hline & B & 4.0 & 8 & 75 & - \\
\hline & $\mathrm{C}$ & 6.0 & - & 78 & - \\
\hline \multirow[t]{4}{*}{6} & & & $6 a$ & - & 6d \\
\hline & A & 0.25 & 92 & - & - \\
\hline & B & 0.25 & 96 & - & - \\
\hline & $\mathrm{C}$ & 0.50 & 94 & - & - \\
\hline
\end{tabular}

${ }^{a}$ Method A: (vinylsilane $+i$-AmONO + glacial $\left.\mathrm{HOAc}\right)+($ glacial $\mathrm{HOAc}+$ conc $\mathrm{HCl})$. Method B: (vinylsilane $+i-\mathrm{AmONO})+\left(\mathrm{Me}_{3} \mathrm{SiCl}\right)$. Method $\mathrm{C}$ : (vinylsilane $+i$-AmONO) in $\mathrm{CH}_{2} \mathrm{Cl}_{2}+\left(\mathrm{Me}_{3} \mathrm{SiCl}\right.$ in $\mathrm{CH}_{2} \mathrm{Cl}_{2}$ ).

${ }^{\mathrm{b}}$ The conversion was about $40 \%$. The yields of the products are based on recovered $\mathbf{5}$.

The 2-trimethylsilylnorbornane adduct (6a) is the most stable adduct and the only product formed under all the three reaction conditions employed to generate NOCl. In the case of 1trimethylsilylcyclohexene- $\mathrm{NOCl}$ addition, the primary adduct $\mathbf{2 a}$ is so unstable that, instead of forming the isolable dimer, it undergoes further reaction rapidly to give 1,2-dichloro-1nitrosocyclohexane (2c), and $\alpha$-chlorocyclohexanone (2d) if $\mathrm{NOCl}$ is generated under aqueous acidic condition. The other four adducts 1a, 3a-5a could be isolated in the form of solid dimeric 
diazene dioxides, provided they were isolated quickly enough from the reaction mixture at about $-10{ }^{\circ} \mathrm{C}$, after allowing reasonable time required for adding the reagents $(i$-AmONO $+\mathrm{HOAc}+$ $\mathrm{HCl}$ or $i-\mathrm{AmONO}+\mathrm{Me}_{3} \mathrm{SiCl}$ ) to generate $\mathrm{NOCl}$. Though the reaction between $\mathrm{NOCl}$ and vinylsilane is instantaneous depending on the rate of $\mathrm{NOCl}$ generation the primary adducts undergo further reaction to give the secondary products. The time recorded for each reaction in Table 1 was the optimum that gave the best yield of the chloronitroso dimer. In the case of 2trimethylsilylnorbornane adduct $\mathbf{6 a}$, because of its relatively high stability the time allowed for the reaction was not much of a deciding factor.

The isolated $\alpha$-chloro- $\beta$-nitrososilane dimers 1a, 3a-5a on further treatment with $\mathrm{NOCl}$ at $20{ }^{\circ} \mathrm{C}$, instantaneously produced the corresponding 1,2-dichloro-1-nitroso compounds $\mathbf{1 c - 5 c}$ in quantitative yield, while 6a remained unchanged (Table 2).

Table 2. $\mathrm{NOCl}$ addition to 1a, 3a-6a by Method $\mathrm{C}$

\begin{tabular}{cccc}
\hline Compound & Time (min) & Product & Yield (\%) \\
\hline 1a & 30 & $\mathbf{1 c}$ & 93 \\
$\mathbf{3 a}$ & 15 & $\mathbf{3 c}$ & 95 \\
$\mathbf{4 a}$ & 15 & $\mathbf{4 c}$ & 91 \\
$\mathbf{5 a}$ & 20 & $\mathbf{5 c}$ & 85 \\
$\mathbf{6 a}$ & \multicolumn{3}{c}{ No reaction } \\
\hline
\end{tabular}

The dimers 1a, 3a-6a produced the corresponding $\alpha$-chloroketones $\mathbf{1 d}, \mathbf{3 d - 6 d}$ in high yield when hydrolyzed with dilute $\mathrm{HCl}$ in dioxane at room temperature (Table 3). The presence of levulinic acid enhanced the rate of hydrolysis considerably. ${ }^{17}$

Table 3. Levulinic acid hydrolysis of 1a, 3a-6a

\begin{tabular}{ccccc}
\hline Compound & Temperature $\left({ }^{\circ} \mathrm{C}\right)$ & Time $(\mathrm{h})$ & Product & Yield $(\%)$ \\
\hline $\mathbf{1 a}$ & r.t & 2 & $\mathbf{1 d}$ & 91 \\
$\mathbf{3 a}$ & r.t & 0.5 & $\mathbf{3 d}$ & 81 \\
$\mathbf{4 a}$ & r.t & 0.5 & $\mathbf{4 d}$ & 88 \\
$\mathbf{5 a}$ & r.t & 0.5 & $\mathbf{5 d}$ & 84 \\
$\mathbf{6 a}$ & 50 & 3 & $\mathbf{6 b}$ & 88 \\
& 75 & 5 & $\mathbf{6 d}$ & 92 \\
\hline
\end{tabular}

To compare the effect of $\mathrm{Me}_{3} \mathrm{Si}$ group on tautomerization of 1a-5a, we prepared the unsilylated $\mathrm{NOCl}$ adducts 7-11 from cyclopentene, cyclohexene, cycloheptene, cyclooctene and cyclododecene, under identical condition (Scheme 3). 


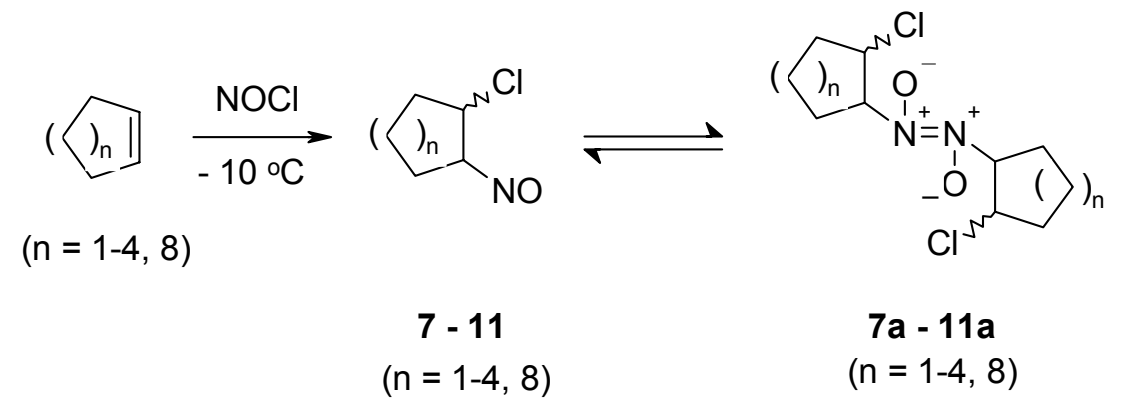

\section{Scheme 3}

The adducts 7-11, which were isolated only as dimers 7a-11a were found to be far more stable both in solid state and in solution, from which they could be recovered unchanged even after several days at room temperature. In contrast, the $\mathrm{Me}_{3} \mathrm{Si}$ containing adducts $\mathbf{1 a}, \mathbf{3 a - 5 a}$ had to be recrystallized extremely cautiously from their saturated solutions in dichloromethanepetroleum ether $(4: 1 \mathrm{v} / \mathrm{v})$ at lower than $-5{ }^{\circ} \mathrm{C}$. Otherwise, they would tautomerize to $\alpha$ chlorooximes $(\mathbf{1 b}, \mathbf{3 b}-\mathbf{5 b})$, or would undergo further hydrolysis to $\alpha$-chloroketones $(\mathbf{1 d}, \mathbf{3 d}-\mathbf{5 d})$. Rapid tautomerization of 1a, 3a, and $\mathbf{4 a}$ was noted during the recording of their NMR spectra in $\mathrm{CDCl}_{3}$ when a ${ }^{13} \mathrm{C}$ signal due to oxime carbon appeared within $30 \mathrm{~min}$ after dissolving each adduct in $\mathrm{CDCl}_{3}$.

The conspicuous propensity of $\alpha$-chloro- $\beta$-nitrososilanes 1a-5a to tautomerize as compared to much higher stability of their unsilylated analogues 7a-11a, which need more vigorous condition for tautomerization, is undoubtedly attributable to the involvement of silicon in the tautomerization process of the former compounds. However, one can also notice a remarkable variation along 1a-6a in their tendency to tautomerize. The adduct 2-trimethylsilyl-2-chloro-3nitrosobicyclo[2.2.1] heptane (6a) requires heating for $3 \mathrm{~h}$ at $50{ }^{\circ} \mathrm{C}$ in dioxane in the presence of levulinic acid and dilute $\mathrm{HCl}$ to form its oxime $\mathbf{6 b}$ with silicon intact. Further hydrolysis to $\alpha-$ chloroketone $6 \mathbf{d}$ occurs only on heating for a longer time at higher temperature $\left(5 \mathrm{~h}\right.$ at $\left.75{ }^{\circ} \mathrm{C}\right)$ (Scheme 4).

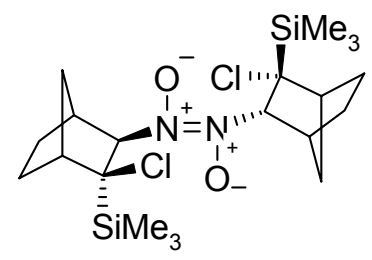

$6 a$

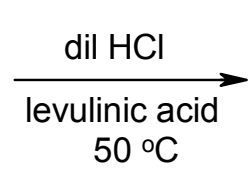
$50{ }^{\circ} \mathrm{C}$

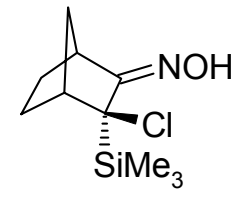

$6 b$

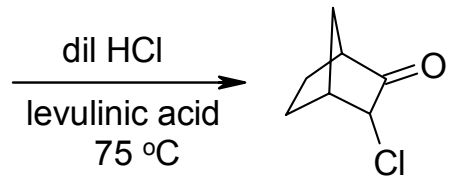

6d

\section{Scheme 4}

On the contrary, the cyclohexane derivative 2a is so unstable that it could not even be detected, but only its secondary product $\mathbf{2 c}$ could be isolated, which would be accompanied by 
$\alpha$-chloroketone $\mathbf{2 d}$, when the reaction is run under aqueous condition. Among others the cyclopentane derivative $\mathbf{1 a}$ is considerably more stable than $\mathbf{2 a}$, while the cycloheptane and cyclooctane derivatives $\mathbf{3 a}$ and $\mathbf{4 a}$ are moderately stable. The cyclododecane derivative $\mathbf{5 a}$ is much more unstable than $\mathbf{1 a}, \mathbf{3 a}$, and $\mathbf{4 a}$, and it could be isolated only in very small amounts.

It is known that oximes react readily with $\mathrm{NOCl}$ to form gem-chloronitroso compounds and the mechanism has been worked out by Kyung and Clapp. ${ }^{18}$ The extraordinary ease with which the 1,2-dichloro-1-nitroso compounds $\mathbf{1 c - 5 c}$ are produced clearly indicates that the oximes $\mathbf{1 b} \mathbf{- 5 b}$ are forming as intermediates, which react with $\mathrm{NOCl}$ to produce 1c-5c (Scheme 5).

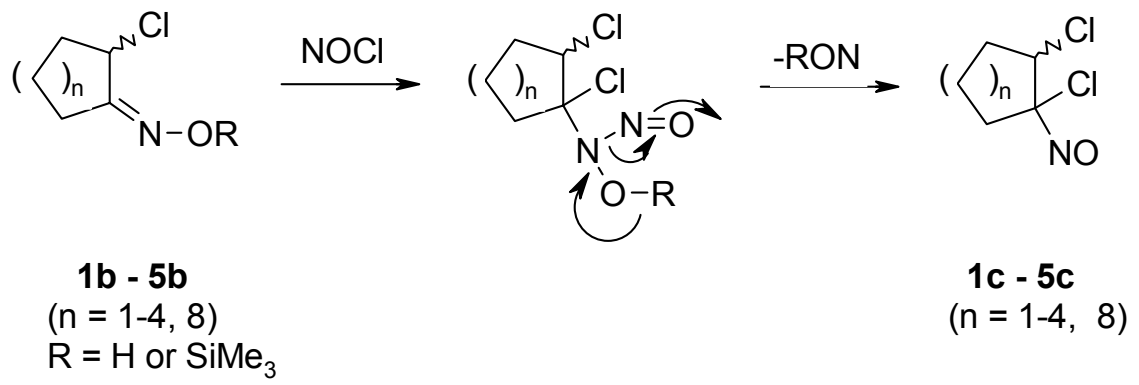

\section{Scheme 5}

We have isolated the oxime $\mathbf{4 b}(\mathrm{R}=\mathrm{H})$ in the reaction of $\mathrm{NOCl}$ with $\mathbf{4}$. However, oximes $\mathbf{1 b}$ $\mathbf{3 b}$ and $\mathbf{5 b}$ were not detected. It should be noted that while the oxime $\mathbf{4 b}$ has lost silicon at -10 ${ }^{\circ} \mathrm{C}$, the oxime $\mathbf{6 b}$ retained silicon even after acid catalyzed hydrolysis of $\mathbf{6 a}$ at $50{ }^{\circ} \mathrm{C}$. Since $\mathbf{6 a}$ does not tautomerize during $\mathrm{NOCl}$ addition, it is clear that it does not give 2,3-dichloro-2-nitroso norbornane. The driving force for this effortless process of tautomerization of $\alpha$-chloro- $\beta$ nitrososilanes 1a-5a, we presume, is due to interaction of oxygen of nitroso group with silicon as shown for 2a, in Scheme 6, when they are close enough for overlap of non-bonding electrons of oxygen with silicon $d$ orbitals and are in contact for sufficient time to establish the O-Si bond. These factors are dependent upon the conformational characteristics of adducts 1a-6a. Based on this concept, it is easy to understand why the norbornane derivative 6a where $\mathrm{NO}$ and $\mathrm{Me}_{3} \mathrm{Si}$ cannot come close enough is so remarkably stable as compared to other adducts 1a-5a, especially $\mathbf{2 a}$, which could not even be detected. It is also easily understandable how the other $\alpha-$ chloro- $\beta$-nitrososilanes 1a, and 3a-5a show varying degrees of stability, which is ascribable to the considerable range of conformational flexibility of these ring systems. ${ }^{19}$

As has already been reported, ${ }^{8}$ the $\mathrm{NOCl}$ addition to cycloalkenyltrimethylsilanes leads to $\mathrm{cis}$ stereochemistry with $\mathrm{Cl}$ bonding to the $\alpha$-carbon and $\mathrm{NO}$ to the $\beta$-carbon, which results in the $\mathrm{Me}_{3} \mathrm{Si}$ and the $\mathrm{NO}$ groups adopting trans geometry. The most stable conformation of 1trimethylsilyl-1-chloro-2-nitrosocyclohexane 2a is very likely to be as shown in Scheme 6, with the $\mathrm{Me}_{3} \mathrm{Si}$ and $\mathrm{NO}$ groups occupying e,e-trans position. This is a highly favourable geometrical setting for oxygen of NO to establish bond with silicon through the interaction of non-bonding 
electrons with the empty $d$ orbitals of silicon or C-Si $\sigma^{*}$ orbital. This would lead to reorganization of various bonds to give eventually the oxime $\mathbf{2 b}$.

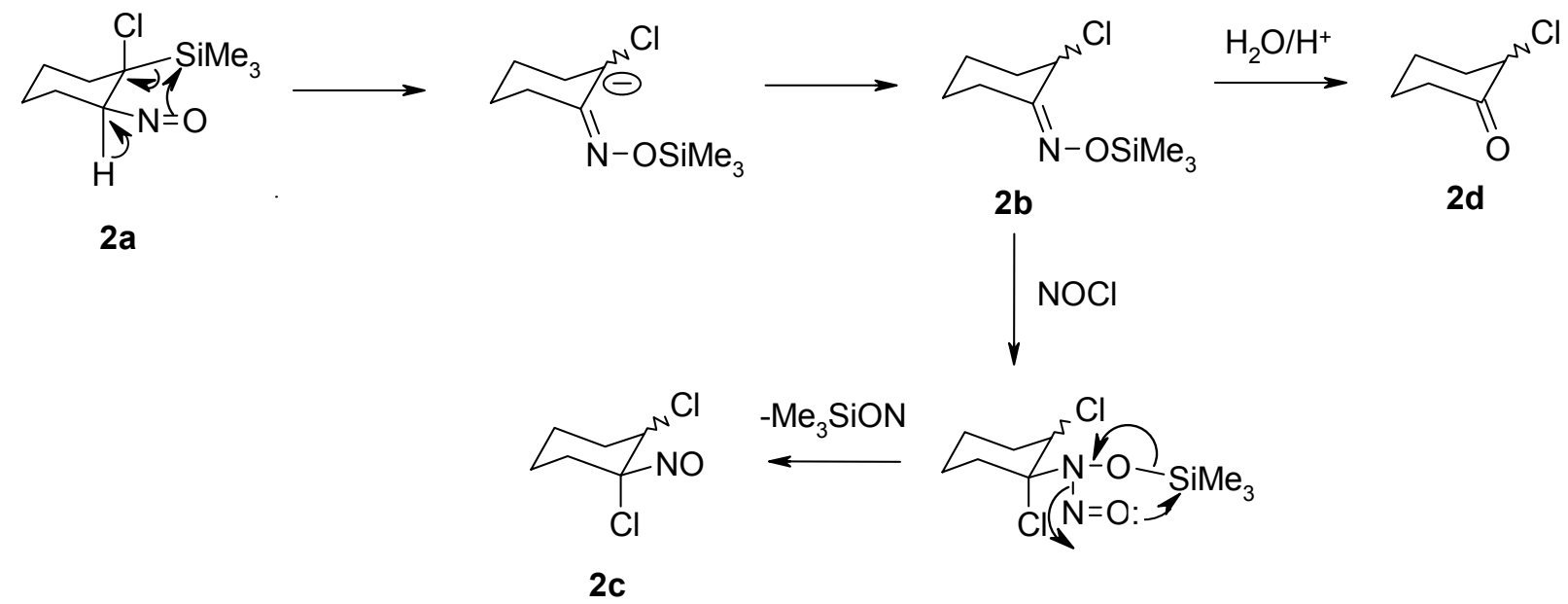

\section{Scheme 6}

Under aqueous acidic condition the oxime $\mathbf{2 b}$ hydrolyzes to $\alpha$-chloroketone $\mathbf{2 d}$. Thus the ease of formation of oxime from the monomeric adduct is directly related to the conformational diversity of the ring which would allow the two groups, $\mathrm{NO}$ and $\mathrm{Me}_{3} \mathrm{Si}$, to come together within an effective interacting distance. This argument explains why the norbornane derivative 6a exhibits high stability, which is attributable to its rigidity that does not permit $\mathrm{NO}$ and $\mathrm{Me}_{3} \mathrm{Si}$ to come close enough. It should also be noted that $\mathbf{6 a}$ hydrolyzes to its oxime $\mathbf{6 b}$ only under forced condition and that too without the loss of silicon (Scheme 4), indicating that silicon does not play any role in tautomerization of monomeric $\mathbf{6 a}$, which is similar to tautomerization of the unsilylated chloronitrosocycloalkanes 7-11.

Because the five membered ring adduct 1a has presumably half-chair conformation, ${ }^{20}$ the separation between $\mathrm{NO}$ and $\mathrm{Me}_{3} \mathrm{Si}$ here is probably midway between that in $\mathbf{2 a}$ and $\mathbf{6 a}$. Hence it is far more stable than 2a. Nevertheless, it tautomerizes smoothly as it can undergo some conformational changes. Since the other three $\alpha$-chloro- $\beta$-nitrososilanes 3a-5a have many more conformational possibilities, ${ }^{20}$ the ease of interaction of $\mathrm{NO}$ and $\mathrm{Me}_{3} \mathrm{Si}$ groups in these molecules is somewhere between $\mathbf{1 a}$ and $\mathbf{2 a}$, and it is reflected in their reactivity relative to the other adducts, being that between $\mathbf{1 a}$ and $\mathbf{2 a}$.

Mechanistically, the formation of the 1,2-dichloro-1-nitroso compounds $\mathbf{1 c - 5 c}$ is also possible by the reaction of $\mathrm{NOCl}$ with 1-chlorocycloalkenes, ${ }^{7}$ which can in principle be formed as intermediates from the primary adducts of reaction as depicted in Scheme 7. 


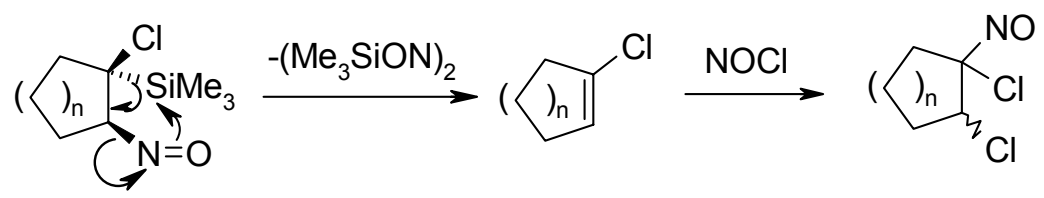

\section{Scheme 7}

However, we have noted in separate control experiments that the addition of NOCl to 1chlorocycloalkenes is very slow and usually incomplete even after $10 \mathrm{~h}$, while 1trimethylsilylcycloalkenes $\mathbf{1 - 5}$ react almost instantaneously to yield the 1,2-dichloro-1-nitroso compounds. Similar results have been observed by others in the addition of NOCl to 1chloroolefins. $^{21}$ Secondly, 1-chlorocycloalkenes have not been detected in our present work, which should have been possible in view of the fact that they add NOCl slowly. Thirdly, the oximes seem to react faster with $\mathrm{NOCl}$ than the starting 1-trimethylsilylcycloalkenes, as a result of which the former are difficult to be isolated or detected in the reaction. We succeeded in isolating the $\alpha$-chlorocyclooctanone oxime (4b), but not its silylated analogue, from 1trimethylsilylcyclooctene-NOCl reaction. It is worth mentioning here that twelve membered 1trimethylsilylcyclododecene (5) is a mixture of cis:trans isomers in a ratio 48:52, and that trans isomer reacts relatively faster with $\mathrm{NOCl}$ than the cis isomer, as observed by the enrichment of cis vinylsilane in the un-reacted $\mathbf{5}$ when the molar ratio of $\mathrm{NOCl}$ is insufficient to consume $\mathbf{5}$ completely.

From these considerations it is clear that the preparation of 1,2-dichloro-1-nitroso compounds is best achieved by the reaction of vinylsilanes (and not vinylchlorides) with excess $\mathrm{NOCl}$ as it occurs under very mild conditions and gives excellent yields. 1,2-Dichloro-1-nitroso compounds are dark blue liquids that are sensitive to heat and light. Some of them dimerize below $0{ }^{\circ} \mathrm{C}$ to white crystalline solids. They are characterized with complete spectral data for the first time in the present work.

\section{Regioselective 1,2-carbonyl migration}

1,2-Carbonyl shift is a useful transformation in organic synthesis. Paquette and coworkers ${ }^{10}$ have achieved this by LAH reduction of $\alpha$-silyl epoxides followed by oxidation-desilylation of the resulting $\beta$-silanols.

The reaction of $\mathrm{NOCl}$ with vinylsilanes described here provides a better alternative to achieve the same end with an additional chloro functional group in the $\alpha$-position. Ketones can be converted by different methods to vinylsilanes, in which silicon would be bound to the carbonyl carbon of the ketone. ${ }^{22}$ Since the addition of $\mathrm{NOCl}$ is regioselective to form $\alpha$-chloro- $\beta$ nitrososilane (as dimer) in high yield under solvent-free condition, the hydrolysis of the adduct leads to chloroketone product in which the new carbonyl function is placed on the carbon adjacent to the original keto carbon of the starting ketone (Scheme 8). 


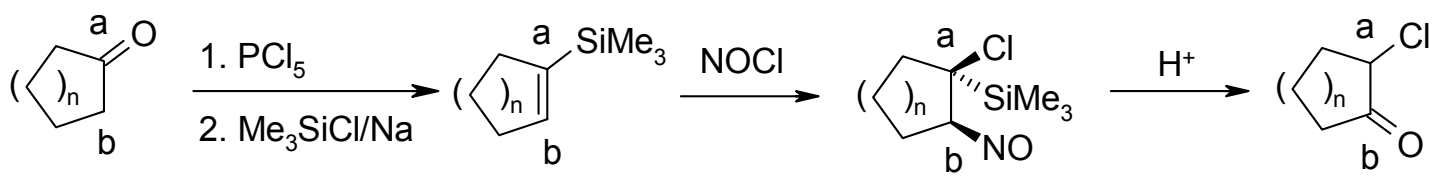

\section{Scheme 8}

This sequence offers a simple procedure for 1,2-transposition of a carbonyl group via vinylsilanes. Moreover, chlorine being introduced in the $\alpha$-position, this provides an additional advantage of regioselectivity as $\alpha$-chloroketones find many synthetic applications. ${ }^{4}$

\section{$\beta$-Aminosilanes}

The reduction of nitroso group in $\alpha$-chloro- $\beta$-nitrososilanes $1 \mathbf{a}, \mathbf{3 a}, \mathbf{4 a}$, and $\mathbf{6 a}$ can be easily accomplished with $\mathrm{SnCl}_{2}-\mathrm{HCl}$, but for the competing protodesilylation in the strong acid medium. Lithium aluminium hydride (LAH) was found to be the most suitable for reducing $\alpha$ chloro- $\beta$-nitrososilanes 1a, 3a, 4a, and 6a. The LAH reduction when carried out at room temperature provided exclusively dechlorinated product $1 \mathrm{e}$ in case of 2-chloro-1-nitroso-1trimethylsilylcyclopentane (1a), while the other adducts $\mathbf{3 a}, \mathbf{4 a}$, and $\mathbf{6 a}$ provided the $\beta$ aminosilanes 3e, $4 \mathbf{e}$ and $\mathbf{6 e}$ respectively without chlorine being lost. However, the adduct 1a when reduced at $-5{ }^{\circ} \mathrm{C}$, provided a mixture of amines 1e and 1f. Surprisingly, reductive dechlorination, which usually occurs at reflux conditions was not observed for the adduct $6 \mathbf{a}$ even when refluxed with excess LAH.

The amines 1e, 1f, 3e, $\mathbf{4 e}$ and $\mathbf{6 e}$ obtained as viscous residues were characterized by converting them to suitable derivatives.

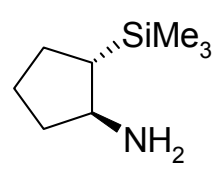

1e

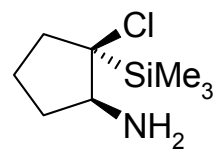

$1 f$

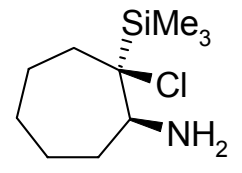

$3 e$

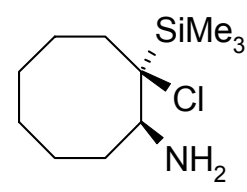

$4 e$

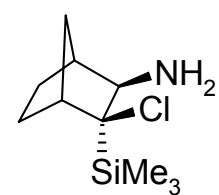

$6 e$

The amines 1e, 1f, and 6e were converted to crystalline acetyl derivatives $\mathbf{1 g}, \mathbf{1 h}$ and $\mathbf{6 f}$ respectively.

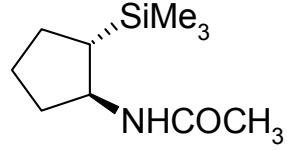

$1 \mathrm{~g}$

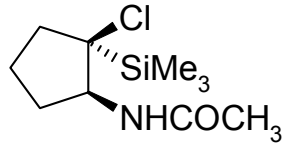

$1 \mathrm{~h}$<smiles>CC(=O)NC1C2CCC(C2)C1(Cl)Cl</smiles>

$6 f$ 
Table 4. LAH reduction of $\alpha$-chloro- $\beta$-nitrososilanes 1a, 3a, 4a and $6 \mathbf{a}$

\begin{tabular}{ccccc}
\hline$\alpha$-chloro- $\beta$-nitrososilane & $\beta$-aminosilane & Temperature & Time $^{\mathrm{a}}$ & Yield (\%) \\
\hline $\mathbf{1 a}$ & $\mathbf{1 e}$ & r.t & $8 \mathrm{~h}$ & 74 \\
$\mathbf{1 a}$ & $\mathbf{1 e}+\mathbf{1 f}$ & $-5^{\circ} \mathrm{C}$ & $10 \mathrm{~h}$ & 80 \\
$\mathbf{3 a}$ & $\mathbf{3 e}$ & r.t & $45 \mathrm{~min}$ & 68 \\
$\mathbf{4 a}$ & $\mathbf{4 e}$ & r.t & $30 \mathrm{~min}$ & 61 \\
$\mathbf{6 a}$ & $\mathbf{6 e}$ & r.t & $18 \mathrm{~h}$ & 78 \\
\hline
\end{tabular}

${ }^{\text {a }}$ Time recorded for reduction of $10 \mathrm{mmol}$ of $\alpha$-chloro- $\beta$-nitrososilane

The investigation of IR spectrum of $\mathbf{1 g}, \mathbf{1 h}$, and $\mathbf{6} \mathbf{f}$ reveal some interesting facts. While the NH stretching and bending vibrations in $\mathbf{1 g}$ appear at 3297 and $1559 \mathrm{~cm}^{-1}$, in both $\mathbf{1 h}$ and $\mathbf{6 f}$ they appear at 3266 and $1569 \mathrm{~cm}^{-1}$. It is very much apparent that the absence of chlorine in $\mathbf{1 g}$ makes the N-H bond different from what it is in $\mathbf{1 h}$ and $\mathbf{6 f}$, which show the same values for the $\mathrm{NH}$ stretching and bending frequencies. Therefore, it would be difficult not to infer that the influence of chlorine on $\mathrm{NH}$ bond in $\mathbf{1 h}$ and $\mathbf{6} \mathbf{f}$ is the same in both. It is also noteworthy that carbonyl stretching in both $\mathbf{1 h}$ and $\mathbf{6 f}$ is at $1647 \mathrm{~cm}^{-1}$, while it is at $1652 \mathrm{~cm}^{-1}$ in $\mathbf{1 g}$. Even NMR signals for $\mathrm{NH}$ proton in $\mathbf{1 h}$ and $\mathbf{6 f}$ are similar, with $\delta 5.27$ and $\delta 5.38$ respectively, while the NH proton signal for $\mathbf{1 g}$ is at $\delta 6.05$. With these data we presume that whatever geometrical correlation exists between $\mathrm{NH}$ and $\mathrm{Cl}$ in $\mathbf{6} \mathbf{f}$ also exists in $\mathbf{1 h}$, which is obviously absent in $\mathbf{1 g}$.

The amine 3e was converted to corresponding picrate $\mathbf{3 f}$ and phenyl thiourea derivative $\mathbf{3 g}$ as it did not form good acetyl derivative.

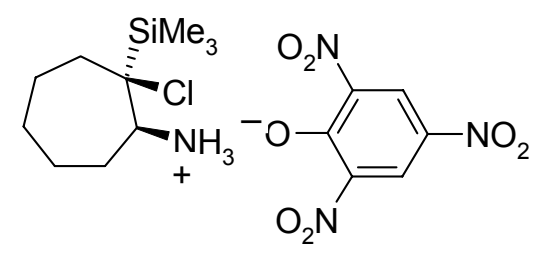

$3 f$

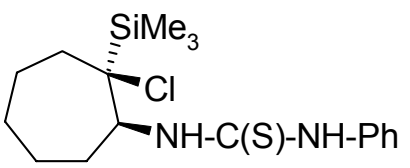

$3 g$

No suitable derivative of the amine $4 \mathbf{e}$ could be made. However, $4 \mathbf{e}$ was purified to about $99 \%$ by bulb-to-bulb distillation and characterized by its NMR and IR spectra.

As reported previously, ${ }^{8}$ the regio- and stereochemistry of addition in case of adducts $\mathbf{1 a}$ and 6a was established by single crystal X-ray diffraction studies. During this study, the reduction of $\alpha$-chloro- $\beta$-nitrososilanes to corresponding amino derivatives, and characterization of their derivatives further established the reversal of regiochemistry. The appearance of the peak at $67.98 \mathrm{ppm}$ as a signal from tertiary carbon atom in the ${ }^{13} \mathrm{C}$ NMR DEPT spectrum of picrate $\mathbf{3 f}$ is a clear indication of the fact that the chlorine atom and the $\mathrm{Me}_{3} \mathrm{Si}$ group are on the same carbon in the precursor $\mathbf{3 a}$. 


\section{Crystal structure of the amide $6 f$}

In our investigation of the single crystal X-ray structure ${ }^{23}$ of the amide derivative $\mathbf{6 f}$, surprisingly we have not observed the $-\mathrm{C}=\mathrm{O} \ldots \mathrm{H}-\mathrm{N}$ - interaction commonly found in amides. ${ }^{24}$ Instead, a less common, $\mathrm{C}-\mathrm{H} \ldots \mathrm{N}$ intermolecular interaction ${ }^{25}$ between the amide nitrogen and the methyl hydrogen was observed as depicted in Figure 1.

The donor-acceptor separation $\mathrm{C} \ldots \mathrm{N}$ is $2.836 \AA$, and the $\mathrm{C}-\mathrm{H} \ldots \mathrm{N}$ angle is found to be $111.05^{\circ}$. Interestingly, the two molecules involved in the $\mathrm{C}-\mathrm{H} . . \mathrm{N}$ interaction are enantiomeric pairs, which is preserved throughout the crystal motif. In a bonding contact, the donor-protonacceptor angle should be more than $90^{\circ}$, and when the angle is near or equal to $180^{\circ}$, it is called a linear contact. In the crystal structure of $\mathbf{6 f}$, the angle is well above the lower limit of $90^{\circ}$, but the contact is not quite linear.

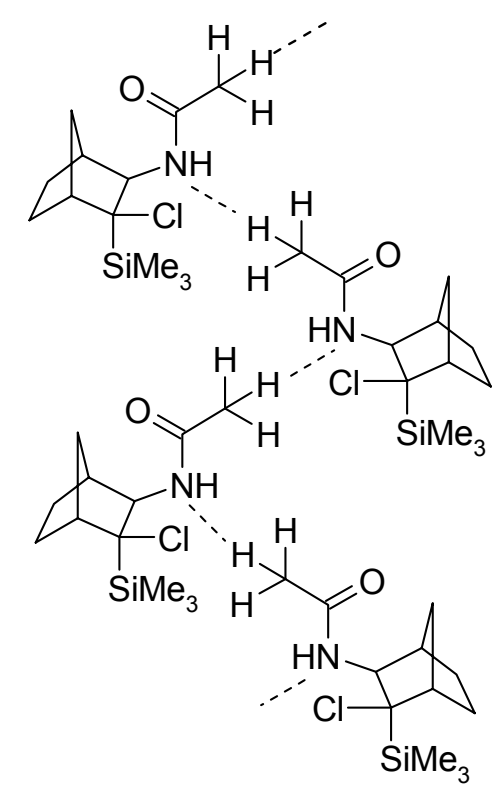

\section{Figure 1}

To our knowledge, this is the first observation of an amide having C-H... N interaction in preference to the usual $\mathrm{N}-\mathrm{H} . . . \mathrm{O}$ interactions, which is surprisingly absent in this structure. The participation of the hydrogen atoms attached to a methyl group in C-H...O interaction is well documented in the literature. ${ }^{26}$ However, the preferential bonding with nitrogen as an acceptor observed in this study is novel. The X-ray structure analysis also indicates intramolecular C$\mathrm{H} . . . \mathrm{Cl}$ interaction between the syn hydrogen atom at the bridge methylene and the chlorine atom. 


\section{Conclusions}

Not only the regioselectivity of $\mathrm{NOCl}$ addition to cycloalkenyltrimethylsilane, but also the further transformation of the resulting chloronitroso adduct to its tautomeric oxime is controlled by silicon through its interaction with $\beta$-nitroso group, which is dictated by the conformational mobility of the ring that allows the two interacting groups to approach within a favourable distance. The primary adducts can be further converted smoothly to 1,2-dichloro-1-nitroso derivatives in high yield, and this seems to be the best method for the preparation of these compounds. The dimeric adducts can be isolated under controlled and solvent free conditions, (the fact that the solvent is not needed indicates that this method is environmentally desirable, ${ }^{27}$ ) and are easily hydrolysable to $\alpha$-chloroketones, in which the keto function is shifted to the adjacent carbon and the chlorine is attached to the carbon of the original carbonyl carbon. This is a simple yet efficient method for regio controlled $\alpha$-chloroketones from vinylsilanes. Further, the $\alpha$-chloro- $\beta$-nitrososilanes serve as useful precursors to $\beta$-aminosilanes, which are novel class of compounds with potential synthetic utility.

\section{Experimental Section}

General Procedures. Melting points were determined by capillary method and are uncorrected. IR spectra (400-4000 $\mathrm{cm}^{-1}$ ) were recorded in $\mathrm{KBr}$ pellets for solids and as thin film between $\mathrm{NaCl}$ plates for liquids on a Nicolet impact 400D single beam instrument. ${ }^{1} \mathrm{H}$ and ${ }^{13} \mathrm{C} \mathrm{NMR}$ spectra were recorded at room temperature in $\mathrm{CDCl}_{3} / \mathrm{DMSO}-\mathrm{d}_{6}$ solution and referenced to TMS (0 ppm) using a JEOL $300 \mathrm{MHz}$ or Brucker AC-250 spectrometers. GC analysis was done on a Varian Vista 6000 instrument using 15\% FFAP on chromosorb W column (2 m X 2 mm i.d). Elemental analyses were performed with a Carlo Elba 1160 instrument.

The starting cycloalkenyltrimethylsilanes 1-6 were synthesized according to known procedure. ${ }^{28}$

\section{General procedure for NOCI addition to cycloalkenyltrimethylsilanes 1-6}

Method A. In a $50 \mathrm{~mL}$ two-necked flask, cycloalkenyltrimethylsilane (10 mmol) was cooled to $10{ }^{\circ} \mathrm{C}$ in an ice-salt bath. iso-Amylnitrite $(12 \mathrm{mmol})$ and glacial acetic acid $(1 \mathrm{~mL})$ were introduced into the flask. The mixture was kept stirred magnetically at $-10{ }^{\circ} \mathrm{C}$. A mixture of glacial acetic acid and conc $\mathrm{HCl}(3: 1 \mathrm{v} / \mathrm{v})$ was added slowly till the reaction was complete (as indicated by GC). Initially a greenish solution was formed which turned blue on further addition of NOCl. A white solid separated out from the blue solution was rapidly filtered, washed with cold ethanol $(5 \mathrm{~mL})$ and dried. The formation of white solid dimeric adduct was instantaneous for the vinylsilane $\mathbf{6}$. For other vinylsilanes the formation of white solid took different lengths of time depending on factors like rate of addition of $\mathrm{NOCl}$, and the rate of stirring. The best possible dimeric adduct yields and the reaction time are reported in Table 1. After filtering off the dimeric adduct, the blue coloured filtrate was diluted with water $(10 \mathrm{~mL})$, and extracted with 
$\mathrm{CH}_{2} \mathrm{Cl}_{2}$. The extracts were washed with water, saturated $\mathrm{NaHCO}_{3}$, and brine, dried over $\mathrm{Na}_{2} \mathrm{SO}_{4}$, filtered and concentrated. The residue was chromatographed on silica gel (60-120 mesh), first eluted with petroleum ether $\left(40-60{ }^{\circ} \mathrm{C}\right)$ to give the 1,2-dichloro-1-nitrosocycloalkane as a blue liquid, followed by elution with $1 \%$ ethyl acetate in petroleum ether $\left(40-60{ }^{\circ} \mathrm{C}\right)$ to give $\alpha$ chloroketone as a colourless to pale yellow liquid. After chromatographing once more the 1,2dichloro-1-nitrosocycloalkane was obtained in $>99 \%$ purity.

Method B. In a $50 \mathrm{~mL}$ two-necked flask, a mixture of cycloalkenyltrimethylsilane (10 mmol) and iso-amylnitrite $(15 \mathrm{mmol})$ was cooled to $-10{ }^{\circ} \mathrm{C}$ in an ice-salt bath. A freshly distilled sample of $\mathrm{Me}_{3} \mathrm{SiCl}(15 \mathrm{mmol})$ was added slowly at a rate of 1 drop per $10 \mathrm{~min}$ with efficient stirring. After the reaction is complete (as indicated by GC), it was worked up as mentioned in method A above.

Method C. To a stirred solution of cycloalkenyltrimethylsilane $(10 \mathrm{mmol})$ and iso-amylnitrite (12 mmol) in $10 \mathrm{~mL}$ of dry $\mathrm{CH}_{2} \mathrm{Cl}_{2}$ was added $\mathrm{Me}_{3} \mathrm{SiCl}(12 \mathrm{mmol})$ in dry $\mathrm{CH}_{2} \mathrm{Cl}_{2}(5 \mathrm{~mL})$ at -10 ${ }^{\circ} \mathrm{C}$. At the end of the reaction (as indicated by GC), the bluish-green solution was diluted with $\mathrm{CH}_{2} \mathrm{Cl}_{2}(15 \mathrm{~mL})$ and transferred to a separatory funnel, washed with water, saturated $\mathrm{NaHCO}_{3}$, water, brine, dried over $\mathrm{Na}_{2} \mathrm{SO}_{4}$, filtered and concentrated. The removal of solvent resulted in a white solid in the case of vinylsilane 6. In other cases a greenish residue was obtained which was chromatographed on silica gel to isolate the blue coloured 1,2-dichloro-1-nitrosocycloalkane compound as described in method $\mathrm{A}$ above.

1a. mp 110-112 ${ }^{\circ} \mathrm{C} ;{ }^{1} \mathrm{H}$ NMR $\left(\mathrm{CDCl}_{3}\right)$ (dimer) $\delta$ : $0.1(9 \mathrm{H}, \mathrm{s}), 1.6-1.9(3 \mathrm{H}, \mathrm{m}), 2.18(2 \mathrm{H}, \mathrm{m}), 2.7$ $(1 \mathrm{H}, \mathrm{m}), 5.81(1 \mathrm{H}, \mathrm{t}, J=8.0 \mathrm{~Hz}) ;{ }^{13} \mathrm{C} \mathrm{NMR}\left(\mathrm{CDCl}_{3}\right)$ (dimer) $\delta:-3.17,21.17,27.73,38.76,66.94$, 69.68; IR (KBr, cm $\left.{ }^{-1}\right)$ 2960, 2919, 1455, 1388, 1228, 1253, 1171, 845, 757; Anal. Calcd. for $\mathrm{C}_{8} \mathrm{H}_{16}$ ClNOSi: C, 46.70; H, 7.84; N, 6.81. Found: C, 46.71; H, 8.02; N, 6.83.

3a. mp 90-92 ${ }^{\circ} \mathrm{C} ;{ }^{1} \mathrm{H}$ NMR $\left(\mathrm{CDCl}_{3}\right)$, (monomer-dimer mixture in solution) $\delta: 0.16$ (s), 0.19 (s) (together $9 \mathrm{H}), 1.57-1.96(7 \mathrm{H}, \mathrm{m}), 2.13-2.64(3 \mathrm{H}, \mathrm{m}), 4.33$ (dd, $J=2.4,1.8 \mathrm{~Hz}$, monomer), and 5.87 (dd, $J=2.1,1.8 \mathrm{~Hz}$, dimer) (together 1H); IR (KBr, $\mathrm{cm}^{-1}$ ) 2934, 2872, 1460, 1212, 1253 , 1186, 850, 762; Anal. Calcd. for $\mathrm{C}_{10} \mathrm{H}_{20}$ ClNOSi: C, 51.37; H, 8.62; N, 5.99. Found: C, 51.43; H, $8.77, \mathrm{~N}, 6.17$.

4a. $\mathrm{mp} 85-87{ }^{\circ} \mathrm{C} ;{ }^{1} \mathrm{H} \mathrm{NMR}\left(\mathrm{CDCl}_{3}\right)$, (monomer-dimer mixture in solution) $\delta: 0.15$ (s), 0.25 (s) (together $9 \mathrm{H}), 1.5-1.9(8 \mathrm{H}, \mathrm{m}), 2.1-2.7(4 \mathrm{H}, \mathrm{m}), 4.6(\mathrm{~m}$, monomer) and $6.01(\mathrm{~m}$, dimer) (together 1H); IR (KBr, cm $\left.{ }^{-1}\right)$ 2945, 2867, 1476, 1450, 1228, 1248, 1191, 845, 762; Anal. Calcd. for $\mathrm{C}_{11} \mathrm{H}_{22}$ CINOSi: C, 53.31; H, 8.95; N, 5.65. Found: C, 53.32; H, 9.23; N, 5.92.

6a. mp 150-152 ${ }^{\circ} \mathrm{C} ;{ }^{1} \mathrm{H}$ NMR $\left(\mathrm{CDCl}_{3}\right)$ (dimer) $\delta$ : $0.3(9 \mathrm{H}, \mathrm{s}), 1.2-1.7(5 \mathrm{H}, \mathrm{m}), 2.5(2 \mathrm{H}, \mathrm{m}), 2.73$ $\left(1 \mathrm{H}\right.$, br. s), $4.93(1 \mathrm{H}, \mathrm{s}) ;{ }^{13} \mathrm{C} \mathrm{NMR}\left(\mathrm{CDCl}_{3}\right)$ (dimer) $\delta:-0.67,25.59,26.37,38.08,41.33,50.43$, 68.12, 74.88; IR ( $\left.\mathrm{KBr}, \mathrm{cm}^{-1}\right)$ 2991, 2960, 2882, 1248, 1232, 839, 756; Anal. Calcd. for $\mathrm{C}_{10} \mathrm{H}_{18} \mathrm{ClNOSi}$ : C, 51.82; H, 7.83; N, 6.04. Found: C, 51.97, H, 7.90; N, 6.16.

1c. $\mathrm{mp} 71-72{ }^{\circ} \mathrm{C}\left\{1\right.$ it. $\left.{ }^{21} \mathrm{mp} 69-70{ }^{\circ} \mathrm{C}\right\} ;{ }^{1} \mathrm{H} \mathrm{NMR}\left(\mathrm{CDCl}_{3}\right) \delta: 2.0-2.3(2 \mathrm{H}, \mathrm{m}), 2.48(1 \mathrm{H}, \mathrm{m}), 2.63$ $(1 \mathrm{H}, \mathrm{m}), 2.85(2 \mathrm{H}, \mathrm{m}), 4.72(1 \mathrm{H}, \mathrm{t}, J=6.6 \mathrm{~Hz}) ;{ }^{13} \mathrm{C} \mathrm{NMR}\left(\mathrm{CDCl}_{3}\right) \delta: 21.44,34.67,35.21,66.08$, 118.43; IR (KBr, cm ${ }^{-1}$ ) 3069, 2986, 2960, 2898, 1434, 1316, 1279, 1233, 1078, 964, 897, 788, 674; Anal. Calcd. for $\mathrm{C}_{5} \mathrm{H}_{7} \mathrm{Cl}_{2} \mathrm{NO}$ : C, 35.74; H, 4.20; N, 8.34. Found: C, 35.48; H, 3.97; N, 8.08. 
2c. Blue liquid; ${ }^{1} \mathrm{H}$ NMR $\left(\mathrm{CDCl}_{3}\right) \delta$ : 1.63-2.10 (6H, m), 2.48-2.72 (2H, m), $5.1(1 \mathrm{H}, J=1.8,3.3$ $\mathrm{Hz}) ;{ }^{13} \mathrm{C} \mathrm{NMR}\left(\mathrm{CDCl}_{3}\right) \delta: 21.08,21.84,31.01,31.91,61.10,109.18$; IR (neat, $\mathrm{cm}^{-1}$ ) 2950, 2867, 1590, 1574, 1455, 855, 710, 643; Anal. Calcd. for $\mathrm{C}_{6} \mathrm{H}_{9} \mathrm{Cl}_{2} \mathrm{NO}$ : C, 39.59; H, 4.98; N, 7.69. Found: C, 39.79; H, 4.77; N, 7.75.

3c. Blue liquid; ${ }^{1} \mathrm{H}$ NMR $\left(\mathrm{CDCl}_{3}\right) \delta$ : 1.55-2.10 (6H, m), 2.31-2.82 (4H, m), $5.08(1 \mathrm{H}, \mathrm{m}) ;{ }^{13} \mathrm{C}$ NMR $\left(\mathrm{CDCl}_{3}\right) \delta: 21.49,24.36,26.99,31.18,33.47,64.82,113.58$; IR (neat, $\mathrm{cm}^{-1}$ ) 2940, 2867, 1574, 1460, 1352, 1279, 876, 855, 622; Anal. Calcd. for $\mathrm{C}_{7} \mathrm{H}_{11} \mathrm{Cl}_{2} \mathrm{NO}: \mathrm{C}, 42.88 ; \mathrm{H}, 5.65$; $\mathrm{N}$, 7.14. Found: C, 42.67; H, 5.56; N, 7.01.

4c. Blue liquid; ${ }^{1} \mathrm{H}$ NMR $\left(\mathrm{CDCl}_{3}\right) \delta$ : 1.56-2.10 (8H, m), 2.19-2.82 (4H, m), $5.09(1 \mathrm{H}, \mathrm{m})$; IR (neat, $\mathrm{cm}^{-1}$ ) 2929, 2857, 1574, 1455, 1336, 757; Anal. Calcd. for $\mathrm{C}_{8} \mathrm{H}_{13} \mathrm{Cl}_{2} \mathrm{NO}$ : C, 45.73; H, 6.24; N, 6.67. Found: C, 46.03; H, 6.20; N, 6.81 .

5c. $\mathrm{mp} 58-60{ }^{\circ} \mathrm{C} ;{ }^{1} \mathrm{H}$ NMR $\left(\mathrm{CDCl}_{3}\right) \delta$ : 1.4-1.6 (12H, m), 2.2-2.6 (6H, m), $3.25(2 \mathrm{H}, \mathrm{m}), 4.68(1 \mathrm{H}$, d, $J=10.8 \mathrm{~Hz}) ;{ }^{13} \mathrm{C} \mathrm{NMR}\left(\mathrm{CDCl}_{3}\right) \delta: 19.96,21.35,22.58,22.64,22.77,24.77,25.47,25.84$, 30.51, 32.27, 66.32, 112.12; IR (neat, $\mathrm{cm}^{-1}$ ) 2940, 2867, 1584, 1564, 1471, 1445, 1352, 731, 540; Anal. Calcd. for $\mathrm{C}_{12} \mathrm{H}_{21} \mathrm{Cl}_{2} \mathrm{NO}$ : C, 54.14; H, 7.95; N, 5.26. Found: C, 53.98; H, 8.02; N, 5.02.

1d. bp 55-56 ${ }^{\circ} \mathrm{C} / 3$ Torr $\left\{\right.$ lit. ${ }^{4,17,29} 87-90{ }^{\circ} \mathrm{C} / 23$ Torr $\} ;{ }^{1} \mathrm{H}$ NMR $\left(\mathrm{CDCl}_{3}\right) \delta: 1.9-2.4$ (6H, m); 4.15 $\left(1 \mathrm{H}, \mathrm{t}, J=7.2 \mathrm{~Hz}\right.$ ); IR (neat, $\mathrm{cm}^{-1}$ ) 2966, 2924, 1755, 1155, 959, 684 .

2d. bp 79-81 ${ }^{\circ} \mathrm{C} / 10$ Torr $\left\{\right.$ lit. $4,17,2977-80{ }^{\circ} \mathrm{C} / 10$ Torr $\} ;{ }^{1} \mathrm{H}$ NMR $\left(\mathrm{CDCl}_{3}\right)$ 8: 1.7-2.5 (8H, m), 4.4 $(1 \mathrm{H}, \mathrm{m})$; IR (neat, $\mathrm{cm}^{-1}$ ) 2950, 2867, 1729, 1450, 1264, 1067, 721.

3d. bp 85-87 ${ }^{\circ} \mathrm{C} / 6$ Torr $\left\{\right.$ lit. ${ }^{4,17,29} 109-111{ }^{\circ} \mathrm{C} / 27$ Torr $\} ;{ }^{1} \mathrm{H}$ NMR $\left(\mathrm{CDCl}_{3}\right)$ \&: 1.5-2.1 (8H, m), 2.4-2.6 (2H, m), $5.0(1 \mathrm{H}, \mathrm{t}, J=5.1 \mathrm{~Hz})$; IR (neat, $\left.\mathrm{cm}^{-1}\right)$ 2945, 2867, 1714, 1455, 767, 659.

4d. bp 65-67 ${ }^{\circ} \mathrm{C} / 1$ Torr $\left\{\right.$ lit. ${ }^{4,29} 72-74{ }^{\circ} \mathrm{C} / 3$ Torr $\} ;{ }^{1} \mathrm{H}$ NMR $\left(\mathrm{CDCl}_{3}\right)$ 8: 1.6-2.2 (10H, m), 2.5$2.8(2 \mathrm{H}, \mathrm{m}), 4.7(1 \mathrm{H}, \mathrm{t}, J=7.7 \mathrm{~Hz})$; IR (neat, $\left.\mathrm{cm}^{-1}\right)$ 2940, 2862, 1710, 1455, 1264, 762.

5d. $\mathrm{mp} 41-42{ }^{\circ} \mathrm{C}\left\{\right.$ lit. $^{4,29}$ bp $114-117{ }^{\circ} \mathrm{C} / 2$ Torr $\} ;{ }^{1} \mathrm{H}$ NMR $\left(\mathrm{CDCl}_{3}\right) \delta: 1.25(18 \mathrm{H}, \mathrm{m}), 2.0(2 \mathrm{H}$,

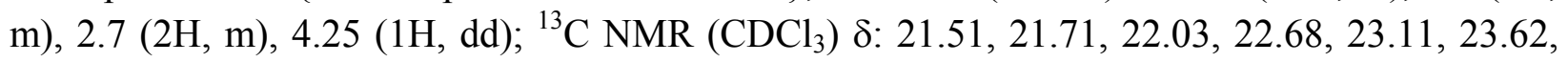
25.52, 25.57, 32.94, 34.01, 62.64, 205.53; IR (KBr, cm $\left.{ }^{-1}\right)$ 2934, 2867, 1719, 1476, $1450,747$.

\section{Levulinic acid hydrolysis}

A mixture of $5 \mathrm{mmol}$ of the dimer $\mathbf{6 a}$ and $20 \mathrm{mmol}$ of levulinic acid in $5 \mathrm{~mL}$ of $2 \mathrm{~N} \mathrm{HCl}$ and 20 $\mathrm{mL}$ of dioxane was stirred at $50{ }^{\circ} \mathrm{C}$ for $3 \mathrm{~h}$ till a clear solution was formed. After the hydrolysis was complete, the mixture was diluted with water $(50 \mathrm{~mL})$, and extracted into ether $(4 \times 25 \mathrm{~mL})$. The combined ether layers were washed with water, saturated $\mathrm{NaHCO}_{3}$, water, and brine, dried over $\mathrm{Na}_{2} \mathrm{SO}_{4}$. After removing the solvent, the residue obtained was a mixture of white solid and traces of pale yellow liquid. Petroleum ether $40-60{ }^{\circ} \mathrm{C}(10 \mathrm{~mL})$ was added to the residue, the white solid was filtered off, washed with petroleum ether $(3 \times 10 \mathrm{~mL})$ to give crude oxime $6 \mathbf{b}$ $(88 \%)$, which was further purified by recrystallization from ethanol-water (3:1) mixture. The combined filtrate was evaporated to give exo-chloronorcamphor $\mathbf{6 d}(10 \%)$.

By heating to $75{ }^{\circ} \mathrm{C}$ for $5 \mathrm{~h}$ the dimer $6 \mathrm{a}$ was completely converted to exo-chloronorcamphor (6d). 
Similarly, by following the above procedure, the hydrolysis of other dimers 1a, 3a, and 4a was carried out at room temperature to give the $\alpha$-chloroketones $1 \mathbf{d}, \mathbf{3 d}$, and $\mathbf{4 d}$ respectively. 6b: $\mathrm{mp} 132-134{ }^{\circ} \mathrm{C} ;{ }^{1} \mathrm{H}$ NMR $\left(\mathrm{CDCl}_{3}\right) \delta: 0.15(9 \mathrm{H}, \mathrm{s}), 1.23-1.80(5 \mathrm{H}, \mathrm{m}), 2.13(1 \mathrm{H}, \mathrm{m}), 2.4(1 \mathrm{H}$, $\mathrm{d}, J=3.0 \mathrm{~Hz}), 3.5(1 \mathrm{H}, \mathrm{d}, J=2.4 \mathrm{~Hz}), 7.1(1 \mathrm{H}, \mathrm{s}) ;{ }^{13} \mathrm{C} \mathrm{NMR}\left(\mathrm{CDCl}_{3}\right) \delta:-2.41,23.01,24.65,36.06$, 37.49, 46.01, 74.06, 171.71; IR (neat, $\mathrm{cm}^{-1}$ ) 3380, 3240, 2960, 2882, 1672, 1440, 1253, 840, 757. 6d. bp $100{ }^{\circ} \mathrm{C} / 10$ Torr $\left\{\right.$ lit. $^{30} 87-89{ }^{\circ} \mathrm{C} / 4.5$ Torr $\} ;{ }^{1} \mathrm{H}$ NMR $\left(\mathrm{CDCl}_{3}\right) \delta$ : 1.3-2.4 (6H, m); $2.7(2 \mathrm{H}$, m), $3.6(1 \mathrm{H}, \mathrm{s})$; IR (KBr, cm $\left.{ }^{-1}\right)$ 2980, 2880, 1760, 1450, 1300, 940, 750, 690, 650.

\section{General procedure for $\mathrm{LAH}$ reduction}

To a stirred solution of LAH $(12.5 \mathrm{mmol})$ in $50 \mathrm{~mL}$ dry ether was added a solution of the $\alpha$ chloro- $\beta$-nitrososilane $(10 \mathrm{mmol})$ in $25 \mathrm{~mL}$ dry ether over a period of $30 \mathrm{~min}$. The stirring was continued for different lengths of time (Table 4) till the completion of the reduction. The supernatant liquid was transferred to a conical flask, and the residue was washed with dry ether. The combined ether layers were washed with water and the $\beta$-aminosilane was extracted into $10 \% \mathrm{HCl}$. The $\mathrm{HCl}$ extract was neutralized with $20 \% \mathrm{NaHCO}_{3}$ and the free amine was extracted back into ether. The ether layer was washed with water, brine, dried over $\mathrm{Na}_{2} \mathrm{SO}_{4}$, and distilled out to obtain the $\beta$-aminosilane as a thick viscous liquid, which was converted to suitable derivative as described below.

Acetyl derivative 1g. The $\beta$-aminosilane 1 e $(5 \mathrm{mmol})$ was treated with $1 \mathrm{~mL}$ of freshly distilled acetic anhydride at $10{ }^{\circ} \mathrm{C}$. After shaking the mixture for $15 \mathrm{~min}$, the excess acetic anhydride was destroyed by adding hot water and heating to $50{ }^{\circ} \mathrm{C}$ for $15 \mathrm{~min}$. The acetyl derivative $1 \mathrm{~g}$, which crystallized out upon cooling to room temperature, was purified by recrystallization from ethanol-water (60: 40) mixture.

1g: $\mathrm{mp} 124-126{ }^{\circ} \mathrm{C} ;{ }^{1} \mathrm{H}$ NMR $\left(\mathrm{CDCl}_{3}\right) \delta: 0.02(9 \mathrm{H}, \mathrm{s}), 1.3-1.8(7 \mathrm{H}, \mathrm{m}), 1.96(3 \mathrm{H}, \mathrm{s}), 4.55(1 \mathrm{H}$, m), 5.27 (NH, br. s); ${ }^{13} \mathrm{C}$ NMR $\left(\mathrm{CDCl}_{3}\right) \delta:-1.66,23.69,23.95,26.15,32.45,35.59,53.26$, 168.65; IR (KBr, cm ${ }^{-1}$ ) 3297, 3090, 2966, 2878, 1652, 1559, 1372, 1295, 1259, 1145, 845, 762; Anal. Calcd. for $\mathrm{C}_{10} \mathrm{H}_{21}$ NOSi: C, 60.25; H, 10.62; N, 7.03. Found: C, 60.06; H, 10.82; N, 6.74.

Acetyl derivative $1 \mathrm{~h}$. The mixture of $\beta$-aminosilanes $1 \mathrm{e}$ and $\mathbf{1 f}(5 \mathrm{mmol})$ obtained from the $\mathrm{LAH}$ reduction of $\mathbf{1 a}$ at $-5{ }^{\circ} \mathrm{C}$ was treated with $1 \mathrm{~mL}$ of freshly distilled acetic anhydride at 10 ${ }^{\circ} \mathrm{C}$. After shaking the mixture for $15 \mathrm{~min}$, the excess acetic anhydride was destroyed by adding hot water and heating to $50{ }^{\circ} \mathrm{C}$ for $15 \mathrm{~min}$. The acetyl derivatives $\mathbf{1 g}$ and $\mathbf{1 h}$, which crystallized out upon cooling to room temperature, were separated by fractional crystallization from ethanolwater (60: 40) mixture. The acetyl derivative 1 g crystallized out first.

1h. mp 104-106 ${ }^{\circ} \mathrm{C} ;{ }^{1} \mathrm{H}$ NMR $\left(\mathrm{CDCl}_{3}\right) \delta: 0.17(9 \mathrm{H}, \mathrm{s}), 1.23-1.61(5 \mathrm{H}, \mathrm{m}), 1.97(3 \mathrm{H}, \mathrm{s}), 4.05(1 \mathrm{H}$, m), 6.05 (NH, br.s); ${ }^{13} \mathrm{C}$ NMR $\left(\mathrm{CDCl}_{3}\right) \delta:-1.78,23.30,24.86,26.85,36.41,56.56,74.69$, 168.61; IR (KBr, cm $\left.{ }^{-1}\right)$ 3266, 3084, 2971, 2971, 1893, 1636, 1564, 1383, 1248, 1171, 902, 860, 752, 622; Anal. Calcd. for $\mathrm{C}_{10} \mathrm{H}_{20}$ CINOSi: C, 51.37; H, 8.62; N, 5.99. Found: C, 51.49; H, 8.54; $\mathrm{N}, 5.70$.

Acetyl derivative 6f. The $\beta$-aminosilane 6 e $(5 \mathrm{mmol})$ was treated with $1 \mathrm{~mL}$ of freshly distilled acetic anhydride at $10{ }^{\circ} \mathrm{C}$. After shaking the mixture for $15 \mathrm{~min}$, the excess acetic anhydride was 
destroyed by adding hot water and heating to $50{ }^{\circ} \mathrm{C}$ for $15 \mathrm{~min}$. The acetic acid formed was neutralized with $20 \% \mathrm{NaHCO}_{3}$, and the acetyl derivative was extracted into ether. The ether layer was washed with water and dried over $\mathrm{Na}_{2} \mathrm{SO}_{4}$ and concentrated to obtain the crude acetyl derivative 6f, which was purified by crystallization from ethanol-water (60: 40) mixture.

6f. $\mathrm{mp} 77-79{ }^{\circ} \mathrm{C} ;{ }^{1} \mathrm{H} \mathrm{NMR}\left(\mathrm{CDCl}_{3}\right) \delta$ : $0.018(9 \mathrm{H}, \mathrm{s}), 1.2-1.7(4 \mathrm{H}, \mathrm{m}), 1.91(3 \mathrm{H}, \mathrm{s}), 2.14(1 \mathrm{H}, \mathrm{m})$,

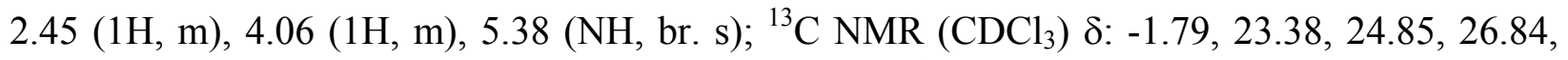
36.41, 44.39, 50.33, 56.59, 74.68, 168.73; IR (KBr, $\left.\mathrm{cm}^{-1}\right)$ 3266, 3079, 2971, 2883, 1647, 1569, 1378, 1253, 1171, 850, 757; Anal. Calcd. for $\mathrm{C}_{12} \mathrm{H}_{22}$ ClNOSi: C, 55.47; H, 8.53; N, 5.39. Found: C, 55.50; H, 8.72; N, 5.10 .

Crystal data for 6f: $\mathrm{C}_{12} \mathrm{H}_{22} \mathrm{ClNOSi}, M=259.85$, orthorhombic, $a=9.480(3) \AA, b=20.931(2) \AA$, $c=7.699(3) \AA, \alpha=90^{\circ}, \beta=90^{\circ}, \gamma=90^{\circ}, U=1527.7(7) \AA^{3}, T=293 \mathrm{~K}$, space group Pna $2_{1}, Z=$ $4, \mu=0.312 \mathrm{~mm}^{-1}, 2157$ reflections measured, 2157 independent reflections $\left(R_{\mathrm{int}}=0.0000\right)$, final $R$ value $[\mathrm{I}>2 \sigma(I)]=0.0735, w R\left(\mathrm{~F}^{2}\right)=0.2180, R($ all data $)=0.1557, w R\left(\mathrm{~F}^{2}\right)=0.2956$.

Picrate 3f. $5 \mathrm{mmol}$ crude $\beta$-aminosilane 3e was dissolved in $2 \mathrm{~mL}$ of $10 \% \mathrm{HCl}$. A saturated solution of picric acid $(2 \mathrm{~mL})$ was added slowly to obtain a yellow precipitate, which was filtered, and purified by crystallization from toluene.

3f. mp 192-196 ${ }^{\circ} \mathrm{C} ;{ }^{1} \mathrm{H}$ NMR (DMSO-d 6 ) $\delta: 0.19$ (9H, s), 1.31-1.53 (11H, m), 3.17 (1H, br.s), $3.46\left(1 \mathrm{H}\right.$, br. s), 7.62 (1H, br. s), $8.38(2 \mathrm{H}, \mathrm{s}) ;{ }^{13} \mathrm{C}$ NMR (DMSO-d 6 ) $\delta:-2.722,21.78,21.88$, 26.40, 28.81, 35.86, 55.58, 67.98, 124.04, 125.10, 141.75, 160.69; IR (KBr, cm $\left.{ }^{-1}\right) 3306,2955$, 2873, 1608, 1588, 1572, 1548, 1368, 1328, 1284, 1268, 1172, 1080, 848, 799, 755, 715; Anal. Calcd. for $\mathrm{C}_{10} \mathrm{H}_{22} \mathrm{ClNSi} . \mathrm{C}_{6} \mathrm{H}_{3} \mathrm{~N}_{3} \mathrm{O}_{7}$ : C, 42.81; H, 5.61; N, 12.48. Found: C, 42.74; H, 5.51; N, 12.74 .

Phenylthiourea derivative 3g. $5 \mathrm{mmol}$ of crude $\beta$-aminosilane $3 \mathbf{e}$ dissolved in ethanol $(1 \mathrm{~mL})$ was treated with phenylisothiocyanate $(1 \mathrm{~mL})$ at $60{ }^{\circ} \mathrm{C}$. The reaction mixture was cooled to $0{ }^{\circ} \mathrm{C}$ to crystallize out the phenylthiourea derivative $\mathbf{3 g}$, which was purified by recrystallization from ethanol.

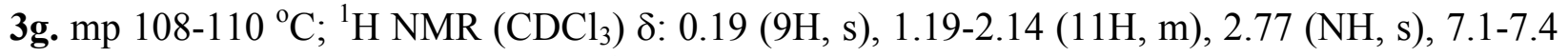
$(5 \mathrm{H}, \mathrm{m}), 7.90(\mathrm{NH}, \mathrm{s})$; IR $\left(\mathrm{KBr}, \mathrm{cm}^{-1}\right)$ 3147, 3038, 2955, 2924, 2857, 1600, 1522, 1450, 1253, 1181, 1103, 850, 757, 700; Anal. Calcd. for $\mathrm{C}_{17} \mathrm{H}_{27} \mathrm{ClN}_{2} \mathrm{SSi}$ : C, 57.51; H, 7.67; N, 7.89. Found: C, 57.81; H, 7.72; N, 8.11.

4e. Pale yellow viscous oil; ${ }^{1} \mathrm{H} \mathrm{NMR}\left(\mathrm{CDCl}_{3}\right) \delta: 0.07(9 \mathrm{H}, \mathrm{s}), 1.48-1.80(10 \mathrm{H}, \mathrm{m}), 2.28(2 \mathrm{H}, \mathrm{m})$, $2.42(1 \mathrm{H}, \mathrm{m}) ;{ }^{13} \mathrm{C} \mathrm{NMR}\left(\mathrm{CDCl}_{3}\right) \delta: 0.72,24.08,24.31,27.31,29.26,30.09,33.51,43.59,66.63$; IR (neat, $\mathrm{cm}^{-1}$ ) 3421, 2934, 2857, 1626, 1476, 1450, 1259, 850, 757. 


\section{Acknowledgements}

This work was partly financed by UGC-DRS and UGC-COSIST programs. MNM thanks UGC,

New Delhi, for a Senior Research Fellowship. Donation of some equipment by Alexander von Humboldt Foundation, Germany, is gratefully acknowledged.

\section{References and Footnotes}

1. (a) Closs, G. L.; Brois, S. I. J. Am. Chem. Soc. 1960, 82, 6068. (b) Tanabe, K.; Hayashi, R. Chem. Pharm. Bull. (Japan). 1962, 10, 1177. (c) Leminer, R. U.; Nagabhushan, T. L.; Neill, I. K. O. Tetrahedron Lett. 1964, 1909. (d) Serfortein, W. J.; Jordan, J. H.; White, J. I. Tetrahedron Lett. 1964, 1069. (e) Hassner, A.; Heathcock, C. J. Org. Chem. 1964, 29, 1350. (f) Ponder, B. W.; Walker, D. P. J. Org. Chem. 1967, 32, 4136. (g) Gupta, M.; Seth, J.; Agarwala, V. G. Ind. J. Chem. 1990, 143. (h) Paul, P. Polyhedron 1993, 12, 2057. (i) Chowdhury, P. K.; Barbaruah, M.; Sharma, P. P. Ind. J. Chem. 1994, 33B, 71.

2. (a) Meinwald, J.; Meinwald, Y. C.; Baker, T. N. J. Am. Chem. Soc. 1963, 85, 2513. (b) Beier, T.; Hauthal, H. G.; Pritzkow, W.; J. Prakt. Chem. 1964, 26, 304. (c) Freeman, F. Chem. Rev. 1975, 75, 471. (d) Gowenlock, B. G.; Richter-Addo, G. B. Chem. Rev. 2004, 104, 3315.

3. (a) Boyer, H. In The Chemistry of the Nitro and Nitroso Groups, Feuer, H. Ed.; Interscience: New York, 1969; Part 1. (b) Glaser, R.; Murmann, R. K.; Barnes, C. L. J. Org. Chem. 1996, 61,1047 and references therein.

4. For other methods of preparation of $\alpha$-chloroketone see (a) Olah, G. A.; Ohannesian, L.; Arvanaghi, M.; Prakash, G. K. S. J. Org. Chem. 1984, 49, 2032. (b) Brummond, K. M.; Gesenberg, K. D. Tetrahedron Lett. 1999, 40, 2231. (c) VanBrunt, M. P.; Ambenge, R. O.; Weinreb, S. M. J. Org. Chem. 2003, 68, 3323 and references therein.

5. Chow, Y. L.; Pillay, K. S.; Richard, R. Can. J. Chem. 1979, 57, 2923.

6. Nelson, D. J. Tetrahedron Lett. 1999, 40, 5823.

7. Kadzyauskas, P. P.; Zefirov, N. S. Russ. Chem. Rev. 1968, 37(7), 543.

8. Mallya M N.; Nagendrappa G.; Prasad, J. S.; Sridhar, M. A.; Lokanath, N. K.; Begum. N. S. Tetrahderon Lett. 2001, 42, 2565.

9. (a) Fleming, I.; Barbero, A.; Walter, D. Chem. Rev. 1997, 97, 2063. (b) Bassindale, A. R.; Glynn, S. J.; Taylor, P. G. In The Chemistry of Organic Silicon Compounds, Rappoport, Z.; Apeloig, Y. Eds.; Wiley: New York, 1998; Vol. 1. (c) Lambert, J. B.; Zhao, Y.; Emblidge, R. W.; Salvador, L. A.; Liu, X.; So, J.-H.; Chelius, E. C. Acc. Chem. Res. 1999, 32, 183.

10. Fristad, W. E.; Bailey, T. R.; Paquette, L. A. J. Org. Chem. 1980, 45, 3028.

11. (a) Cuinico, R. F. Synth. Commun. 1988, 18, 917. (b) Cunico, R. F. J. Org. Chem. 1990, 55, 4474.

12. (a) Nagendrappa, G.; Vidyapati, T. J. J. Organometal. Chem. 1985, 31, 280. (b) Patil, G. S.; Nagendrappa, G. Chem. Commun. 1999, 1079. 
13. (a) Lambert, J. B.; Emblidge, R. W.; Malany, S. J. Am. Chem. Soc. 1993, 115, 1317; (b) Chan, Y. V.; Clark, C.; Giordano, J.; Green, A. J.; Karalis, A.; White, J. M. J. Org. Chem. 1996, 61, 5227.

14. Mallya M. N.; Nagendrappa, G. J. Chem. Soc., Perkin Trans. 2, 2001, 2248-2252.

15. Weiß, R.; Wagner, K. G. Chem. Ber. 1984, 117, 1973.

16. Rao, C. N. R.; Bhaskar, K. R. In: The Chemistry of the Nitro and Nitroso Groups, Feuer, H. Ed.; Interscience: New York, 1969; Part 1.

17. (a) DePuy, C. H.; Ponder, B. W. J. Am. Chem. Soc. 1959, 81, 4629. (b) Ponder, B. W.; Walker, D. P. J. Org. Chem. 1967, 32, 4136.

18. Kyung, J. H.; Clapp, L. B. J. Org. Chem. 1976, 41, 2024.

19. Eliel, E. L.; Wilen, H. S.; Mander, L. N. In: Stereochemistry of Organic Compounds, Wiley: New York, 1994; pp 762-771.

20. Eliel, E. L.; Wilen, H. S.; Mander, L. N. In: Stereochemistry of Organic Compounds, Wiley: New York, 1994; pp 760-761.

21. Ogloblin, K. A.; Grigorova, T. N.; Potekhin, A. A. Zh. Org. Khim. 1969, 5(8), 1360.

22. Weber, W. P. Silicon Reagents for Organic Synthesis; Springer-Verlag: New York, 1983.

23. Nagendrappa, G.; Prasad, J. S.; Mallya, M. N.; Sridhar, M. A.; Lokanath, N. K. (2006) Private communication to the Cambridge Structural Database, deposition number CCDC156782.

24. Jeffrey, G. A.; Saenger, W. Hydrogen Bonding in Biological Structures; Springer: Berlin, 1991.

25. (a) Steiner, T. New J. Chem. 1998, 1099. (b) Mascal, M. Chem. Commun. 1998, 303. (c) Gavezzotti, A. Cryst. Rev. 1998, 7, 5.

26. Desiraju, G. R.; Steiner, T. The Weak Hydrogen Bond in Structural Chemistry and Biology; Oxford University Press: Oxford, 1999; pp 29-121.

27. (a) Tanaka, K.; Toda, F. Chem. Rev. 2000, 100, 1025. (b) Tanaka, K. Solvent-free Organic Synthesis; Wiley-VCH: Weinheim, 2003.

28. Nagendrappa, G. Synthesis 1980, 704.

29. (a) Zakharkin, I.; Korneva, L. A. Bull. Acad. Sci. USSR, Hiv. Chem. Sci. (Engl. Transl.) 1962, 1817. (b) Methoden Org. Chem. (Houben-Wely) 1962, 5/3, 620.

30. (a) Meinwald, J.; Meinwald, Y. C.; Baker, T. N. J. Am. Chem. Soc. 1964, 86, 4074. (b) Ponder, B. W.; Wheat, P. W. J. Org. Chem. 1972, 37, 543. (c) Brown, H. C.; Kawakami, J. H.; Liu, K. T. J. Am. Chem. Soc. 1973, 95, 2209. 